\title{
Enrique Macpherson Mayol
}

\author{
M. PILAR OLIVAR ${ }^{1}$ and PERE ABELLÓ ${ }^{2}$ \\ Institut de Ciències del Mar, CSIC, Pg. Marítim de la Barceloneta 37-49, 08003 Barcelona, Catalunya, Spain. \\ E-mail: polivar@icm.csic.es
}

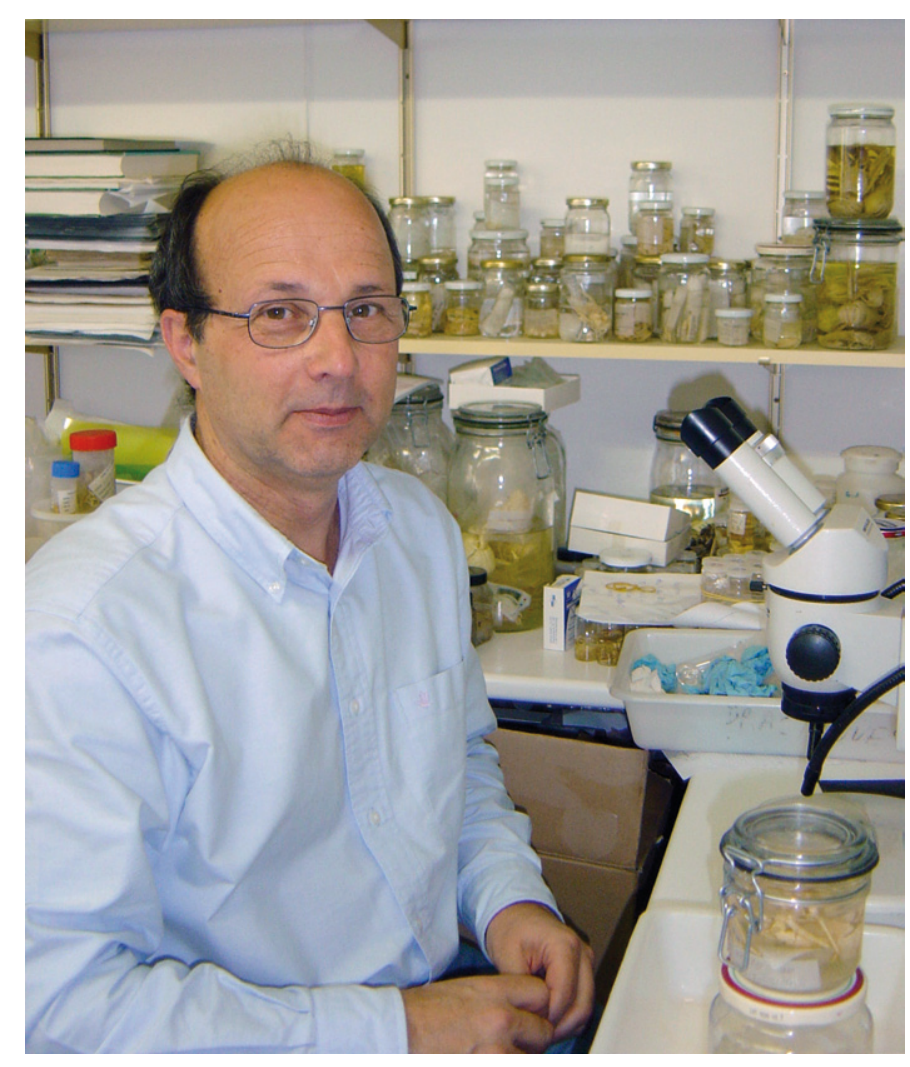

Enrique Macpherson was born in Cádiz (Andalusia, Spain) on 24 April 1951. His paternal father's family, originally from Scotland, had moved to Andalusia to work as shipbrokers and wine producers. From a very early age Macpherson was already a sea lover and put great enthusiasm into finding out everything possible about the fish species that he was able to collect and observe in the areas around his home town. He owned most of the available books on marine zoology and biology. His first-hand contact with nature and later with the academic world forged the naturalistic style that continued throughout his life. He has always been aware that careful observation and awareness of nature provide the solid foundations of scientific knowledge. His clear childhood interest in correct species identification allowed him to attain his present recognition as one of the world's top experts in decapod crustacean taxonomy. 
After spending his youth in Cádiz he moved to Barcelona (Catalonia, Spain) in 1969 to study Biological Sciences at the University of Barcelona. There he met key scientists of the time, who helped to forge his naturalistic and scientific career, such as Prof. Enrique Gadea (Zoology) and Prof. Ramon Margalef (Ecology). During his college years he started working at the Institute of Fisheries Research (Instituto de Investigaciones Pesqueras, IIP) in Barcelona, where he was fully introduced to marine biology. This institution belonged to the Spanish National Research Council (Consejo Superior de Investigaciones Científicas, CSIC) and in 1987 changed its name to the current Institute of Marine Sciences (Institut de Ciències del Mar, ICM). With Macpherson a batch of students also joined the IIP and accompanied him on cruises and in scientific discussions on fisheries and marine biology. His first marine collaborations started under the supervision of Carles Bas i Peired, who was Head of the Marine Resources section (Sardà, 2012). His formal collaboration started in 1974 with a PhD studentship granted by a Spanish development plan (III Plan de Desarrollo). His $\mathrm{PhD}$ thesis entitled "Estudios sobre las relaciones tróficas en peces bentónicos de la costa catalana" focused on trophic relationships in Mediterranean fishes, and was supervised by Carles Bas. He defended his thesis at the University of Barcelona in 1977 before a committee headed by Enrique Gadea. During these first years at the IIP he participated in several research cruises, especially in the eastern central Atlantic (western Sahara) and in the Mediterranean.

In 1981 Macpherson won a permanent staff position at the IIP in Barcelona as a Scientific Researcher (Colaborador Cientifico). From the 1970s to the 1990s Macpherson's research focused on three main subjects: trophic ecology (in the Mediterranean and southeast Atlantic), demersal fisheries management (particularly in the southeast Atlantic), and decapod crustacean faunistics and taxonomy (all over the world). From the beginning he was firmly convinced of the importance of publishing in international journals, though in these earlier years this was not the rule but the exception.

From 1981 to 1991 he led the project "Investigaciones en las costas de Namibia“, which had previously (1974-1980) been headed by Carles Bas. The project was financed by the Spanish Fisheries Secretariat and its main purpose was to sample and monitor the hake populations in Namibian waters. He was the chief scientist of many cruises carried out in the Benguela upwelling region off Namibia. Macpherson continued Bas's endeavours to work far beyond what was strictly expected from the project and made sure to collect a wide range of data on different aspects of the ecosystem so as to gain a good insight into the overall system. He combined sea time (leading 15 one-month cruises) with desk, laboratory and advisory tasks. He was also responsible for presenting to the International Commission for the Southeast Atlantic Fisheries (ICSEAF) the scientific reports prepared with the information

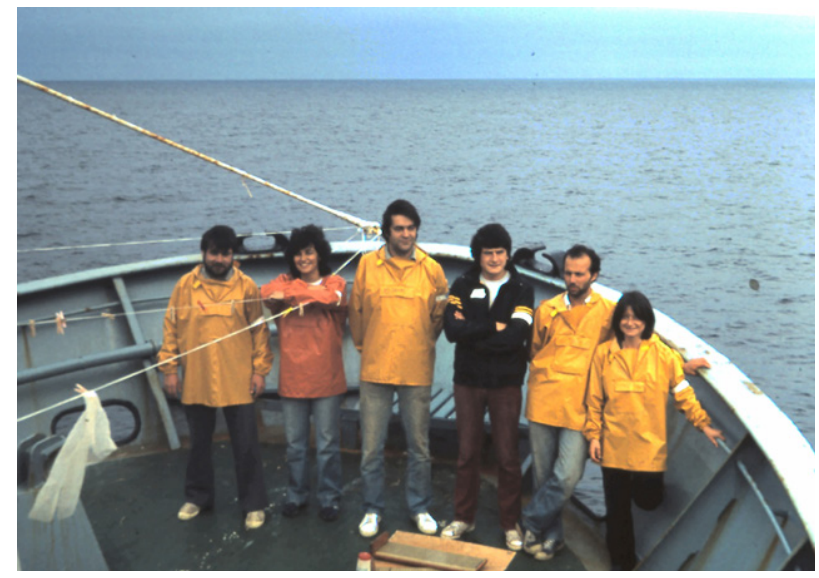

Cruise carried out in the Valdivia Bank (South East Atlantic) in May 1982. From left to right: Jordi Salat, Pilar Sánchez, Pere Rubiés, Arturo Castellón, Enrique Macpherson and M. Pilar Olivar.

obtained from the scientific cruises and from the sampling observers on board fishing ships. He acted as Executive Adjunct Secretary of the ICSEAF in 1980.

He was able to gather a large group of researchers in different specialities: oceanography, plankton, faunistics (fishes, crustaceans, cephalopods, sponges, cnidarians, ascidians, pygnogonids and algae) and population dynamics studies (including growth and modelling). His contact with the academic world, particularly with the University of Barcelona, led to the incorporation of specialists in different fields and of numerous students, who worked on their $\mathrm{PhD}$ theses using information and samples obtained from the project. He always encouraged and promoted young researchers to present their results at international conferences and to publish in high-impact journals. The final balance of the project was 15 completed PhD theses and over 200 scientific publications. In spite of his role as leader of the project and in charge of many of the activities during the cruises, he only authored publications in which he became a really active partner. Of particular relevance was the series Monografías de Zoología Marina launched with the help of Jaume Rucabado, which presented monographic results on the research made on systematics, taxonomy and biogeography of faunistic groups collected in the Benguela upwelling region. The first three issues appeared as volumes of Monografías de Zoología Marina and the last three were special or regular issues of the journal Scientia Marina (http://www.icm. csic.es/scimar), both published by the ICM.

During this period collaborations with scientists of the Sea Fisheries Research Institute (Marine and Coastal Management) of Cape Town, South Africa were established, ranging from joint cruises at sea to interchange of scientists in the laboratories. All of this gave rise to joint publications and firm scientific links that continue to the present. It is also worth mentioning the collaboration with the South African Museum, where Macpherson had the opportunity of examining a large body of samples of decapod crustaceans from the Benguela region which, in some cases, were identified by him. 


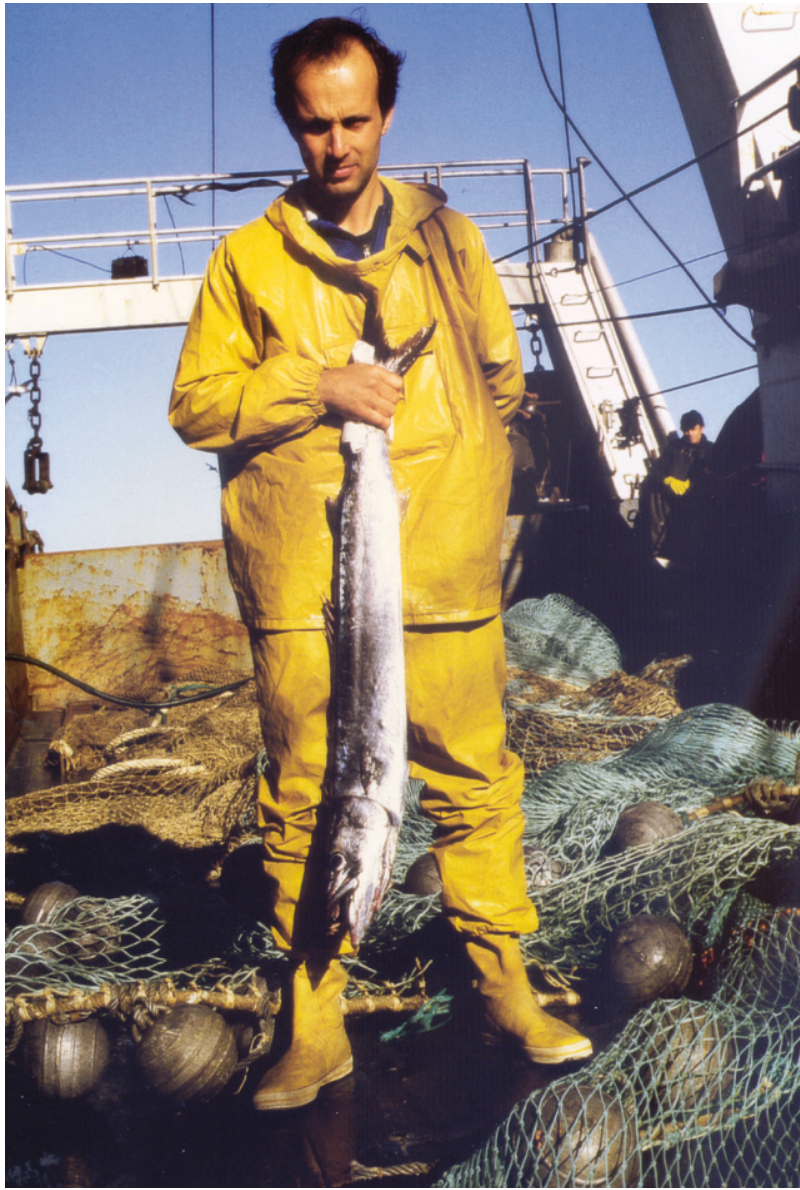

Enrique Macpherson on board the freezer trawler "Chicha Touza" off Namibia during research cruise "Benguela VIII" in 1985.

In spite of the difficulty of obtaining data outside the fisheries, Macpherson promoted the incorporation of conductivity-temperature-depth probes and plankton samplers in the cruises, not an easy task in the commercial fishing trawlers used at the time to carry out the scientific cruises. This certainly needed a good deal of imagination. He also promoted the incorporation of new and pioneering technologies, for that period, such as automatic ichthyometers to obtain information on size-frequency distribution of the exploited fish populations more quickly and easily, the use of on-board computers to feed and save daily information directly on the ship, and the starting of data analysis in almost real time. In this regard we are sure that Macpherson would like us to mention the help of Pere Rubiés in configuring the plankton samplers in the fishing ships, as well as the valuable help of Mario Manríquez, Jordi Salat and many other collaborators.

After being adjunct director for several years during the directorship of Carles Bas (1983-1987), Macpherson was director of the ICM from 1991 to 1994. In 1994 he moved to the Centre for Advanced Studies of Blanes (Centre d'Estudis Avançats de Blanes, CEAB), a recently created interdisciplinary research centre of the CSIC. There he started a new line of research fo- cused on coastal ecology and population biology and genetics of coastal species. This involved intense field work that continues to the present, mostly consisting in diving in the littoral zones of the Mediterranean coast.

Being aware of the importance of actively participating in science management tasks, after his directorship at the ICM he participated in a wide variety of committees, among which it is worth mentioning his work as Coordinator of the Natural Resources area of the CSIC (1996-2000) and his involvement in the Scientific Advisory Committee of the CSIC (20002004). Despite the time-consuming management tasks, Macpherson was able to continue his scientific work and after this period he fully resumed his scientific and advisory activities.

Macpherson has been the principal investigator in 10 research projects at both a national and international level, and has actively participated in a total of 25 . Overall, he authored a total of 209 scientific papers between 1977 and 2012. He has also supervised a total of nine $\mathrm{PhD}$ theses. His field experience is broad, in both research cruises and coastal diving samplings, totalling 18 cruises on board research and fishing ships in the northeast and southeast Atlantic and the Mediterranean Sea, on 16 of which he was Chief Scientist.

As stated above, Macpherson is widely known for his interest in decapod crustacean taxonomy. This interest started when he became aware of the lack of information for properly identifying the crustacean species appearing in the trawl samples onboard research cruises in the South Atlantic. His scientific and naturalistic interest in correctly identifying the species that were captured led him to provide valuable biogeographical information on the species occurring in the area, and to the discovery and description of several new species to science. He therefore focused his interest on increasing knowledge on the biodiversity of this large group of crustaceans, which led him to make important contacts throughout the world and visits to major museums, including the Muséum National

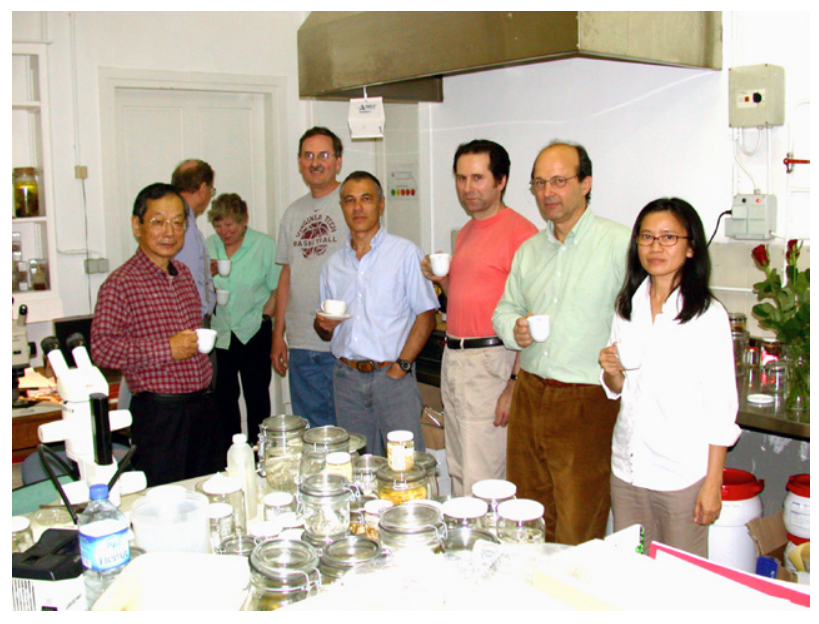

Museum National d'Histoire Naturelle (Paris, France) with anomuran taxonomists in 2007. Macpherson, second from right. 
d'Histoire Naturelle in Paris, which became one of his favourite institutions for escaping from day-to-day work and fully concentrating for a few days or weeks on examining, drawing and describing many new species to science. It is worth mentioning that Macpherson has described over two hundred new species to science, especially of galatheid crabs, including Kiwa hirsuta, which had a great impact under its popular denomination of the Yeti Crab (Macpherson et al. 2006).

\section{DIRECTORSHIP (1991-1994)}

Enrique Macpherson was appointed Director of the ICM in 1991, when the CSIC central administration considered it important for the ICM director to be picked from the local staff. Miquel Alcaraz acted as adjunct director, and José Antonio Fernández and Rita Arias were the administrative department heads.

The ICM was divided into three departments: Marine Biology, Renewable Marine Resources, and Physical Oceanography and Marine Geology. A marine technology unit was thought to be necessary to properly manage Spain's marine research vessels and the Spanish Antarctic base. As ICM's director, Macpherson was involved in the creation of this structural unit, which was necessary to perform top science with high quality equipment, technicians and facilities. This unit first took the name of the Research Vessel Management Unit (Unidad de Gestión de Buques Oceanográficos, UGBO), and later changed its name to the Marine Technology Unit (Unidad de Tecnología Marina, UTM).

Macpherson actively encouraged field work, involving a wide use and optimization of research ships. The fine tuning of the new Spanish research flagship ship Hespérides and its first cruises took place during his mandate, both in Antarctic waters and around the Iberian Peninsula, with broad participation and active involvement of ICM staff. RV García del Cid continued her almost non-stop activities throughout the Mediterranean Sea, all around the Iberian Peninsula, NW Africa and the Canary Islands. Macpherson also strongly supported coastal and littoral research.

One of the important tasks undertaken in this period was the organization of the first management plans to move the ICM laboratory and facilities to new premises. The location of the new laboratory was agreed by the CSIC and the mayor of Barcelona, Pasqual Maragall, together with the other authorities involved. The new building, close to the Olympic harbour in Barcelona and not far from the old location, was inaugurated almost a decade later in 2001.

Collaboration with Catalonia's regional government was also promoted during Macpherson's directorship and, among other projects, it is worth mentioning the contract with the Catalan Water Agency (Agència Catalana de l'Aigua, ACA) to perform studies and monitoring on coastal water quality and on red tides along the coasts of Catalonia. This project has undergone several contract renewals and is still active.

Internationalization through participation in European projects, exchange of scientists and participation in international publications were strongly developing in this period and were actively encouraged by the ICM directorship and CSIC managers in general.

\section{BIBLIOGRAPHY}

Alonso B., Díaz J.I. 2012. Andrés Maldonado López. Sci. Mar. 76: 633-636.

Macpherson E., Jones W., Segonzac M. 2006. A new squat lobster family of Galatheoidea (Crustacea, Decapoda, Anomura) from the hydrothermal vents of the Pacific-Antarctic Ridge". Zoosystema 27(4): 709-723.

Sardà F. 2012. Carles Bas i Peired. Sci. Mar. 76: 425-428.

Biography series ed.: F. Peters. 